\title{
A Project-Based Mechatronics Program to Reinforce Mechatronic Thinking - A Restructuring Experience from the University of Canterbury
}

\author{
XiaoQi Chen*, Paul Gaynor**, Richard King*, Geoff J Chase*, Phil Bones**, Peter Gough**, Richard Duke*** \\ *Department of Mechanical Engineering, University of Canterbury, \\ Private bag 4800, Christchurch 8140, New Zealand. \\ ** Department of Electrical \& Computer Engineering, University of Canterbury, \\ Private bag 4800, Christchurch 8140, New Zealand. \\ *** Dean, College Office, College of Engineering, University of Canterbury, \\ Private bag 4800, Christchurch 8140, New Zealand. \\ Tel: +6433642987 Email: xiaoqi.chen@canterbury.ac.nz
}

\begin{abstract}
The approach taken during restructuring the Mechatronics Program at the University of Canterbury is described, along with challenges faced. The background of the University of Canterbury Mechatronics program is examined, as are the challenges of integrating the program within the Department of Mechanical Engineering and the Department of Electrical \& Computer Engineering. The new Mechatronics program features integrative projects during each of three Professional Education years to reinforce students" "mechatronic" thinking and hands-on abilities. The project-based course "Introduction to Mechatronics Design" features a series of application-oriented laboratory projects using a Programmable Logic Controller (PLC). The restructured program of balanced essential skills training coupled with focus streams of specialization may signal a paradigm shift in engineering education.
\end{abstract}

\section{INTRODUCTION}

Mechatronics is the name coined in the early 1980's for the study of the combined fields of Mechanical Engineering, Electronics and Computers (Ashley, 1997). Since the 1990s, many mechatronics engineering degree programs have been created in tertiary educations throughout the world. They exist at different levels, from Diplomas in mechatronics, Bachelor degrees in mechatronics, to Master degrees in mechatronics. This trend in higher learning institutions has been exacerbated in the advent of rapid development of computer control hardware and software and realisation of the benefits of integrating computer control into electromechanical systems. Computers play a variety of roles in mechatronic systems, from modelling, simulation, validation, visualisation, measurement, data acquisition to digital control (Craig, 2003).

Market drivers, technological advancements, and globalisation of manufacturing are leading to increased interaction between different disciplines - mechanics, electronics, computers, embedded control software, computer control involved in different domains (Vossler et al., 2005). The increasing convergence of mechanical, electrical/electronics and embedded software in design and manufacture of modern electromechanical products has driven the demand for mechatronics system design (Aberdeen Group, 2006). There is also a rising demand of mechatronics engineering studies in the Middle East (Tutunji et al., 2007).

In the USA, there are few mechatronics engineering degree courses although the importance of mechatronics as a new area of expertise has been acknowledged by academics and industry. Many US universities, for example the University of California (Berkeley), Colorado State University, Virginia Polytechnic, and Rensselaer Polytechnic, offer mechatronics engineering courses as technical electives in the Mechanical Engineering curriculum (Das et al., 2005). On the other hand, many universities in Canada, Europe, Asia, Australia and New Zealand are offering mechatronics undergraduate or postgraduate degrees.

Colorado State University restructured its mechanical engineering program with a mechatronics theme. The result is a curriculum with contemporary emphasis, enhanced content, and improved sequencing and coupling of traditional topics including modelling and analysis, computing, electrical circuits and machines, measurements and instrumentation, control theory, and design (Alciatore at al., 2001). Tri-State University institutes weekly projects to provide the students with a hands-on learning experience (Kiefer, 2006). Electrical Engineering at the University of Twente offers the BSc with a one-semester mechatronics related content and a mechatronics design project. It also offers a two-year MSc in Mechatronics, together with the department of Mechanical Engineering (van Amerongen, 2006).

This paper reports the results of mechatronics programme restructuring at the University of Canterbury. It starts with the background of the program and the rationale behind the changes. It then describes the approach to the restructuring exercise. The outcome is the integrative project-based mechatronics program which ensures a project-based course for each of the three Professional Education years. The whole-year project-based mechatronics introductory course 
for the second year of study is presented, an example of application-oriented lab project "Water tank control" being illustrated. Future plans for the program are highlighted.

\section{RATIONALE AND APPROACH}

\subsection{Background and Rationale}

Professional (discipline specialization) Education at the University of Canterbury is contained in the final three years of a four-year education plan. All Engineering students undertake an extensively common first year, termed the Intermediate Year. At the conclusion of their Intermediate Year, students apply for admission to the various professional programs, and are selected based on their preference and performance during that initial year.

In the second year, they are streamed into different engineering programs to undertake further three professional years of training. These engineering degree programs include Mechanical Engineering (ME), Electrical and Electronic Engineering (EEE), Mechatronics, Forestry, Civil Engineering, and Chemical and Processing Engineering.

The mechatronics professional program was started at the University of Canterbury in 2004, with a limited intake of 15 students. It has grown to an intake of 30 students per year in 2007. As in other engineering programs at the University of Canterbury, the mechatronics engineering students take common engineering courses in their first (Intermediate) year. For them to prepare for their mechatronics degree studies, the following courses are taken in their first year: Physics, Chemistry, Engineering Mathematics, Mathematical Modelling and Computation, Engineering Mechanics, and Foundations of Engineering.

While the common engineering courses in the Intermediate Year are fairly standard, the curriculum development for the remaining three Professional Education years of the mechatronics program proves to be challenging. It is always tempting and a matter of convenience to put in place the multi-disciplinary mechatronics engineering undergraduate program by combining essential topics from mechanical engineering, electronics, and computer engineering. The University of Canterbury went down in the similar path at the initiation of its mechatronics program. The program, based in the Department of Mechanical Engineering, was essentially a collection of relevant courses offered in ME, and ECE. There has been a lack of coherence and systemic approach in delivering "synergistic integration of the three components mechanical engineering, electronics, and computer control" which is supposed to be the cornerstone of "Mechatronics". As a result, problems with the program began to surface:

- Students lack prerequisites for some classes. Consequently they have limited choice of electives as their study progresses.

- There were no dedicated mechatronics courses which integrate various mechatronics components to reinforce students' mechatronics design skills.
- There was a lack of sufficient mechatronics project work and laboratories, which makes the program a loose combination of mechanical engineering, and electrical and computer engineering courses.

- Students face timetabling issues, and have concerns of work overload.

These issues had called for revamping and overhaul of the program in order to continue the offering of the degree courses at the time when the original program director retired. During the transition period, Dr. Paul Gaynor (Department of Electrical and Computer Engineering) was selected as the interim program director. Under his direction, the second year course was restructured to include significant mechatronics design content. In August 2006, Professor Richard King (Oregon Institute of Technology, USA) was appointed as a visiting fellow to further the restructuring and to create the new course "ENMT201 Introduction to Mechatronics Design". In the meantime, the University appointed a senior faculty member Associate Professor XiaoQi Chen as the Director of Mechatronics Program to lead the program, who came on board in November 2006.

\subsection{Approaches}

In restructuring the program, a thorough analysis of the existing program was accomplished, present course syllabi and outcomes being examined. A comprehensive survey of various mechatronics engineering programs has been conducted. Feedback from students has been taken into account. It was decided that existing courses must be streamlined and re-aligned, and new courses need to be developed to support the project-based teaching. The important ingredients of a good mechatronics program were quickly identified, namely, project-based mechatronics teaching, hands-on laboratory work, and industry sponsored projects. Key principles and guidelines were adhered to in the program restructuring:

- $\quad$ The program must have strong support and commitment from the departments involved, mainly mechanical engineering, and electrical and computer engineering. It should be cross-department fertilisation to enhance engineering education at the University of Canterbury which has already been enjoying excellent reputation.

- Significant design projects are the focus, with students undertaking a series of designs as they progress through the program.

- $\quad$ Every professional year must have design projects.

- There must be sufficient laboratory work which is carried out concurrently with course work.

- There must be a strong presence of industry interests in the program through project sponsorship and consultation.

The restructuring of the program has to operate with two constraints. One principal constraint is the limitation on 
student contact hours. It would be a simple matter to declare everything taught in both mechanical engineering and electrical and computer engineering as essential, and thus have the mechatronics program contain all of both; the only problem would be that the program would be seven years in length! Clearly, this is not an option.

Another constraint is the need to minimise specialized courses wherever practicable. As the mechatronics program matures and grows, specialized courses will become more frequent as a matter of "fine-tuning" the program. Increased teaching loads due to program growth in both Mechanical Engineering enrolment and Mechatronics enrolment justifies hiring of new faculty members, which will then permit more mechatronics-specific courses.

The restructured program balances essential skill training required for mechatronics, which means equitable involvement from both the Department of Mechanical Engineering (ME) and the Department of Electrical and Computer Engineering (ECE). The relationships between the program and the two departments have been harmoniously tied together through the Board of Studies (BOS) chaired by the Director of the Program. The BOS consisting of the Dean of the College, the Coordinator of ME, the Coordinator of ECE, and key faculty members oversees the program curriculum development.

The mechatronics program has a significant number of core ME courses, but will have extensive training in ECE courses as well. Of necessity, some ME courses are eliminated, combined with other courses, or offered as electives. The program has a close relationship with the Department of Electrical and Computer Engineering. Many of the courses selected for the mechatronics program have their origins in ECE, where such courses fit in with the program design. In other instances, portions of existing courses are mixed with other topics, producing limited coverage of some topics without overloading students by having them take the fulllength ECE course. A limitation exists with ECE courses, since they are all full-year courses; this makes "mix and match" strategies difficult to implement. Nevertheless, it proved possible to include sufficient flexibility in the mechatronics program to allow students to comply with most ECE courses and their pre-requisites. Faculty members who deliver the courses are actively engaged to avoid any gaps in students' pre-requisites as they progress in their professional training.

During curriculum restructuring, we engaged International Advisory Members for their views on our proposed course structure and continual improvement of our course structure. The Erskine Visiting Fellowship, a unique academic exchange scheme at the University, has been used to engage international experts to deliver courses.

We fully recognise that the mechatronics discipline is evolving as the technology progresses at a rapid pace. Industry engagement through an Industry Advisory Board ensures that the Program is relevant to industry needs, and also secures industry-funded projects for the fourth year mechatronics design projects. Some of these projects have evolved into postgraduate projects. Industry advisory members are invited to attend student's project presentations.

\section{INTEGRATIVE PROJECT-BASED MECHATRONICS PROGRAM}

In the new mechatronics curriculum, mechatronics students will encounter mechatronics-specific courses from the beginning of their professional training, namely Introduction to Mechatronics Design in the $2^{\text {nd }}$ year, Mechatronics System Design in th $3^{\text {rd }}$ year, and Mechatronics Project in the $4^{\text {th }}$ year. The new mechatronics course structure is shown in Fig. 1, while the Intermediate Year is not affected by the restructuring.

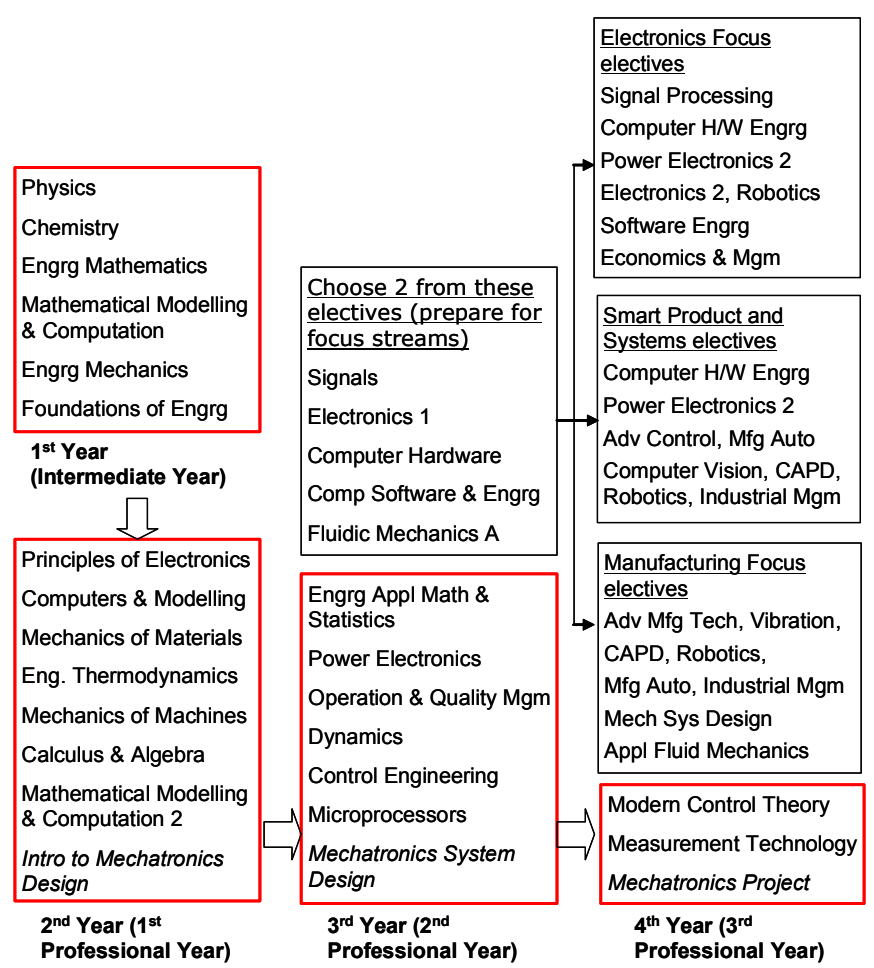

Fig. 1. An overview of the integrative project-based mechatronics program.

What makes this program unique is the emphasis on laboratory exercises and project design from the second year to the fourth year. How else do students learn about mechatronics design except by practicing it? Is there a better way to teach it? We do not believe so. The mechatronics program's greatest strength will be found in projects the students design. There is a design thread from the $2^{\text {nd }}$ year $\left(1^{\text {st }}\right.$ Professional year) all the way to the $4^{\text {th }}$ year $\left(3^{\text {rd }}\right.$ Professional year). Students generally work in groups of two or four, the level of the design challenge rises with progression through the program, and the final result is a concrete demonstrable project - students have the opportunities to design and build. In the new course structure, the $2^{\text {nd }}$ year students are exposed to mechatronics control concepts through the whole year course "Introduction of Mechatronics Design" featuring a series of laboratory projects, at the very beginning of their professional training. 
The second feature of the new course structure is the focus on making the program integrative through projects, i.e. there is an effort made to ensure that a project or assignment in one class is utilized during a project in another class next semester or next year. In this way, students are encouraged to pay attention to lectures and labs in those early classes, since that knowledge gained will be put to use in future project designs. This is intended for the project-based course "Mechatronics System Design" in the $3^{\text {rd }}$ year. Apart from the knowledge on mechanical design, actuators and sensors that are covered in the course, students have to relate other courses such as computer hardware, software and control in their design of mobile machines.

The third feature of the program is industry sponsored final year Mechatronics Projects. The students usually work in groups of three or four, but individual projects are allowed depending on the scope of the project. These projects are jointly co-supervised by an academic member and the industry mentor. As such, the industry sponsors contribute to part of the project costs as well as technical progress of the project. In many cases, the results are adopted by the sponsoring companies.

Finally the restructured program provides flexibility in "fine tuning" individual studies by devising the focus streams in the final year, as shown in Fig. 1. The three focus streams are:

\section{- $\quad$ Manufacturing}

- $\quad$ Smart Products \& Systems

\section{- Electronics}

The recommended streaming caters for students' interests and strength, helps students choose their electives in the $3^{\text {rd }}$ and $4^{\text {th }}$ year, and guides their career development. It is necessary for the students to consider which streams they wish to place their focus on as early as during the $3^{\text {rd }}$ year. Therefore the mechatronics program was planned in such way that electives are available during the 3 rd year. This allows students to take the necessary pre-requisite courses, and select a focus during their final year studies.

In essence, the new program provides a broad coverage of essential contents in mechanical, electronics, computer control and mechatronics design, but allows students to specialise in a focus stream of their choice. Our approach of balanced mechatronics training coupled with some degree of specialisation in the final year appears to be opposite to the generalist approach of most mechatronics programs. Could it be a paradigm shift in engineering education?

\section{LABORATORY-BASED MECHATRONICS DESIGN}

All courses for the $2^{\text {nd }}$ year are prescribed and compulsory. As shown in Fig. 1, these courses include Electronics, Computers \& Modelling, Mechanics of Materials, Mechanics of Machines, Engineering Thermodynamics, Mathematics, Numerical Modelling and Computation 2, and Introduction to Mechatronics Design.
It is always challenging to introduce mechatronics control concepts to the students after they barely understand some basics of engineering from their $1^{\text {st }}$ year courses. They have not learnt much about control theories and computer programming. Because of this fact, many mechatronics programs defer this important part of training to senior years and even postgraduates.

Our view is that the earlier the students are exposed to mechatronics system control, the more effective they are tuned to mechatronics training at the later stages. However the students are just learning about Electronics and microprocessors; and it is too soon to utilize them in a project. Hence the laboratories and project have to be carefully designed so that these hands-on training areas achieve the objectives of reinforcing students' mechatronic thinking and that the students are able to absorb the knowledge.

After careful consideration and evaluation, Programmable Logic Controllers (PLCs) were chosen as the platform for all laboratory work and projects for the $2^{\text {nd }}$ year (first professional year) design course "Introduction to Mechatronics Design" because of its ability to accomplish significant tasks with simple graphical programming. Electronics and computer issues are minimized, and yet the students can readily understand ladder logic diagram, and profit from a significant design challenge.

This whole-year course "Introduction to Mechatronics Design" serves as a foundation for the three professional education years in mechatronics engineering. It covers important topics of mechatronics systems. These topics include mechatronics design approach, PLC, mechatronics components (actuators, sensors, signal conditioning), mechanical design, electrical design, electrical circuit theorems, introduction to control, and introduction to project management. In the electrical design, PSpice and Protel are well covered, and one design assignment for each design software is carried out in the Electronics Design Lab. As for the mechanical design, students use SolidWorks to complete two design projects.

This introductory mechatronics design course with balanced ingredients aims to equip the students with baseline knowledge about mechatronics systems, and basic mechatronics design skills. Emphasis is placed on "Learning by Doing" through a series of mechatronics laboratory projects, which involves PLC programming, sensors, actuators and control, input and output devices, and data acquisition.

The specially-designed laboratory projects using PLC put emphasis on the students' problem-solving and hands-on abilities. This provokes the students to think "mechatronically"; and to link component technologies to integrated mechatronics systems, and theories to applications. It is a deliberate attempt to have the students consider the integration of mechanical (to a less degree), electronic, controls, and computer knowledge in various automation tasks while they take the course work concurrently. 
The key to the success of the design course is the establishment of a Programmable Logic Controller Laboratory. We chose the Omron Sysmac CP1H model and CX-Programmer as the basic platform. The laboratory contains 18 sets of PLC stations. Fig. 2 shows the basic setup of the PLC apparatus which consists of the Omron PLC and relays, the in-house design-and-built terminal junction box and the steel frame for mounting various modules and components and cabling. The close-up of PLC and relays is shown in Fig. 3.

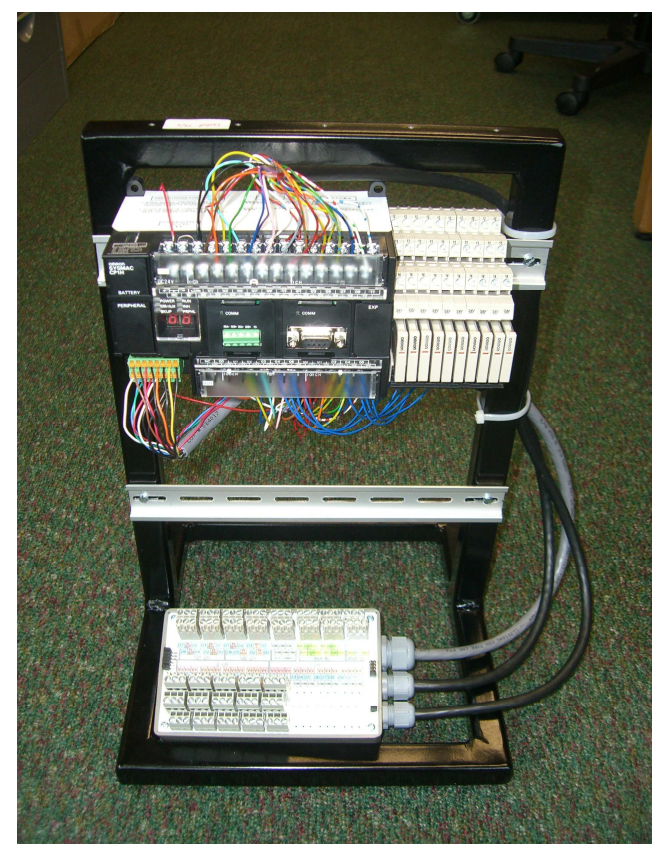

Fig. 2. The basic PLC setup consisting of Omron PLC, relays, a junction box, and a fixturing frame.

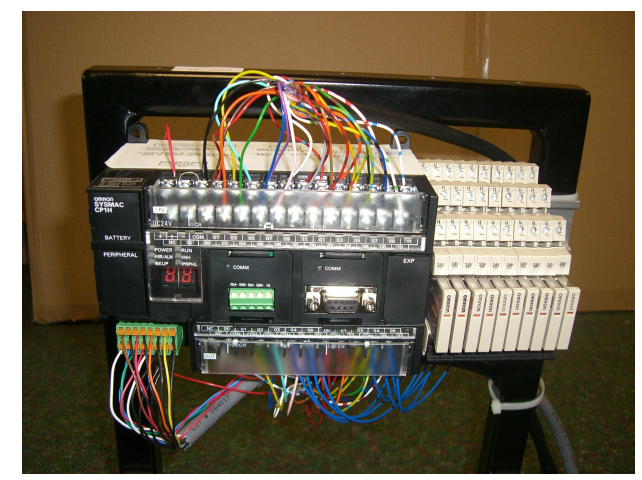

Fig. 3. A close-up of Omron PLC (left) and relays (right).

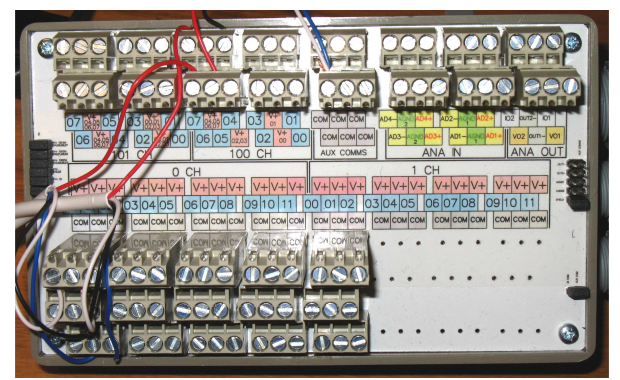

Fig. 4. A close-up of the 4MT junction box.
Students wire the field devices to interface junction box 4MT instead of directly to the input modules and output modules of the PLC. As such, the junction box, as shown in Fig. 4, provides some protection from misuse of the PLCs.

Five application-oreinted PLC lab projects have been designed. Each lab project is a self-contained project excersie addressing a specfic application. These lab projects are:

- Sequencing control using promixity sensors.

- Car washing process automation (buttons and indicators are used simulate various stages of car washing).

- Water tank level control.

- Stepper motor control.

- DC motor velocity control (including optical encoders).

A common application for Programmable Logic Controllers is to control a machine or process. In the lab project "Water tank level control", the PLC is utilised to control the water level in the system tank. The block diagram of the plant to be controlled is shown in Fig. 5.

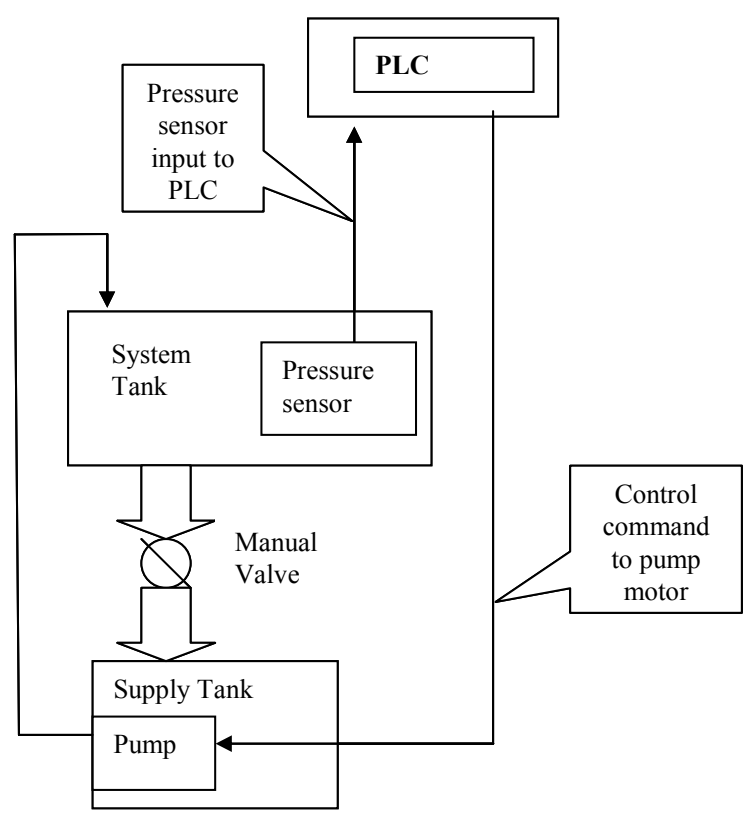

Fig. 5. A block diagram of water tank level control system.

The plant has two tanks, a system tank and a supply tank. The system tank drains water to the supply tank via a manual valve. The pump, switched on/off by a digital output of the PLC, supplies water to the system tank to maintain desired water level. As such the water recycles between the two tanks. Once the valve is set manually, the water flows from the system tank to the supply tank continuously. A pressure sensor measures the water level in the system tank, and the control decision is made based on the water level reading. Additionally, a float switch, hard wired in series with the pump motor, is located in the system tank to prevent overflow in case that the program malfunctions. When the float switch is triggered, the pump stops automatically. The following control steps are defined: 


\section{Read "PRESSURE SENSOR".}

2. If the sensor detects the "UPPPER LEVEL", switch off the "PUMP".

3. If the sensor detects "LOWER LEVEL", switch on "PUMP"

4. If the water level is between "UPPER LEVEL" and "LOWER LEVEL", no action is required.

Students, working in pairs, design a ladder logic diagram to implement the feedback control. Obviously for the plant to work, the flow rate of the supply, once switched on, must be greater the drain. The students are further challenged to make their programs flexible so that the "UPPER LEVEL" and "LOWER LEVEL" can be adjusted in real time. The on-thefly set-point adjustment stimulates students' critical thinking.

Through this lab, the students understand important mechatronics concepts and components: feedback control, pressure sensor, hard-wired safety, actuator (valve), analog input, analog-to-digital conversion, relay to control AC supply to the pump, digital output for on/off control of the pump. In addition to the five laboratory sessions that are completed in the first semester, a design project on elevator control using PLC has also been designed for the second semester of the course.

\section{WORK IN PROGRESS}

The revamping of the mechatronics engineering undergraduate degree program is a work-in-progress. So far the new structure for the $2^{\text {nd }}$ year has been implemented smoothly. The cornerstone course "Introduction to Mechatronics Design" for the $2^{\text {nd }}$ year reinforces students' mechatronics thinking through a series of laboratory projects at the beginning of their professional training.

The new course structure for the $3^{\text {rd }}$ year and $4^{\text {th }}$ year will be implemented in 2008 and 2009 respectively. The key component of the $3^{\text {rd }}$ year training will be "Mechatronics System Design". In addition to the course work, the students are required to draw on knowledge from their pre-requisites they have learnt in the $2^{\text {nd }}$ year, and work as a team to design and build mobile machines. A new faculty member has been appointed to champion this project-based course.

The proposed three focus streams in the final year will be refined. The core (compulsory) course "Measurement Technology" will be created. The elective course "Vibration" will be revived. The new elective course "Robotics" will be developed, and open to all engineering students. As far as the final year mechatronics projects are concerned, more and closer industry collaborations will be sought.

Mechatronics discipline is contemporary and evolving. It is the very nature of mechatronics to change, and the University of Canterbury mechatronics program is no different. While the focus will remain with projects and mechatronics design, developments in other relevant fields will be added to the program over time.

\section{CONCLUSIONS}

The University of Canterbury has taken a systematic approach to restructure all three professional years of the mechatronics program. The new program puts the focus on hands-on training and critical thinking through laboratory work and projects. The early introduction of mechatronics design, anchored by a series of application-oriented laboratories and projects based on Programmable Logic Control, provokes students to think "mechatronically" right from the beginning of their professional training. The flexible approach of coupling broad-based mechatronics training with focus streams of specialisation to some degree may signal a paradigm shift in engineering education.

\section{REFERENCES}

Aberdeen Group, Inc. (2006). The Mechatronics System Design Benchmark Report - Coordinating Engineering Disciplines, August 2006

Alciatore, D.G. and M.B. Histand (2001). Integrating Mechatronics Into a Mechanical Engineering Curriculum. In: IEEE Robotics \& Automation Magazine, June 2001 , pp. $35-38$.

Ashley, S. (1997). Getting a hold on Mechatronics. In: Mechanical Engineering, May 1997, pp. 60-63.

Craig, K. (2003). The role of computers in mechatronics. In: Computer in science and engineering, March/April 2003, pp. 80 -85.

Das, S., M. Krishnan, and S.A. Yost (2005). Work in Progress - The Outgrowth of Mechatronics Curriculum Development Efforts: An Undergraduate Concentration in Mechatronics. In: 35th ASEE/IEEE Frontiers in Education Conference, October 19 - 22, 2005, Indianapolis, IN, USA, pp. F3F-7 to F3F-8.

Hsu, T.R. (1997). Mechatronics - an overview. In: IEEE Transactions on CPMT - Part C, Vol 20, No. 1, January 1997, pp. 4-7.

Kiefer, S. (2006). A project oriented Mechatronics Course. The 10th Mechatronics Forum Biennial International Conference, June 19-21, 2006, Penn State Great Valley, Malvern, PA 19355, USA.

van Amerongen, J (2006). Projects and tools for a mechatronic curriculum. In: The 10th Mechatronics Forum Biennial International Conference, June 19-21, 2006, Penn State Great Valley, Malvern, PA 19355, USA.

Vossler, D. and V. Dutt (2005). Global Trends and Best Practices in Mechatronics - Product Lifecycle management. In: Mechanical Engineering, 10/06/05.

Tutunji, T.A., M. Jumah, Y. Hosamel-deen, and S.A.Rabbo (2007). Mechatronics curriculum development at Philadelphia University in Jordan. In: Mechatronics, Vol. 17, Issue 1, February 2007, Pages 65-71. 